\title{
Arteriovenous Malformations of Face
}

\author{
Karpaga Preethitha .S
}

\begin{abstract}
Arteriovenous malformation (AVM) is an abnormal connection between arteries and veins, bypassing the capillary system (1). They frequently involve the head, neck, and oral cavity. Subdivided into vascular tumors (hemangiomas) and vascular malformations, vascular anomalies remain poorly understood (2). They are generally asymptomatic but sometimes cause pain, bleeding and other complications. This article gives information about the Clinical presentation, Pathogenesis, diagnosis and management methods for the disease.
\end{abstract}

Keywords: Abnormal Connection, Vascular Tumors, Asymptomatic

\section{Introduction}

Arteriovenous malformations (AVMs) are the result of errors of vascular development between the 4th and 6th weeks of gestation. (3) Failure to prune unwanted primitive communications between the arterial and venous systems may result in a malformation. Most of these lesions are obvious at birth while some are obvious during adolescence or adulthood. (4). Approximately $51 \%$ of vascular malformations occur in the head and neck region, and the male-to-female ratio is $1: 1.5(5)$.

Arteriovenous malformations of the head and neck (extracranial) are high-flow lesions and among the most serious of the vascular malformations because they aredifficult to diagnosis, treat, and cure. They grow throughout life with frequent, dramatic, and aggressive growth spurts as a result of various environmental influences. AVMs are very destructive, infiltrative, and often life-threatening secondary to massive bleeding. Most common areas of occurrence are the cheek, lips, neck, scalp, neck, ear, tongue, and mandible. (6) (7)

\section{Classificaion of Vascular Abnormalities:}

The vascular malformations are subdivided into:

I. Vascular tumors-

Hemangiomas

II. Vascular malformations-

1. low-(slow) flow lesions

2. high-(fast) flow lesions: Arteriovenous fistula (AVF), Arteriovenous malformities (AVM)

(8) (2).

\section{Pathogenesis}

Of all vascular anomalies, the pathogenesis of AVMs remains most unclear. It is unknown whether these lesions are congenital, and in case of congenital AVMs, the errors in vasculogenesis causing them are unknown. AVMs are usually present at birth but may not manifest until several years later. Rapid progression may occur during periods of hormonal fluctuations such as puberty, pregnancy, or hormonal therapy. We have recently demonstrated by immuno-histochemistry the presence of progesterone receptors in most AVMs. Interestingly, using the same technique, estrogen receptors were not identified. These findings support the role of hormonal influence on the rapid growth of AVMs. (2) (9)

Trauma may also be a causal factor in AVM formation. A large number of reported cases of AVM in the literature did not present until over 40 years of age. (6) (10) (11) (12). There have been cases where patients with classical AVMs that had a definite history of trauma to a specific site and within a short time had symptoms and signs of a vascular abnormality. Treatment with surgery was undertaken several years after the traumatic event, and both clinically as well as histologically, these abnormalities were consistent with AVM. (2) It is conceivable that these patients may have had subtle or minor trauma which caused an AVF to progress to an AVM. (13)

It has been discovered that AVMs can have large numbers of stem cells that could be responsible for the creation of new blood vessels. This finding may lead to new treatment options such as chemotherapy or anti-angiogenic drugs. Much research is still needed to answer these important questions. (2)

\section{Clinical Presentation}

On physical examination, early AVM lesions may have an overlying vascular blush in the skin similar to an early portwine stain. The underlying tissue is usually thickened and is not fluctuant or compressible but can be pulsatile. The more advanced lesions may have obviously enlarged vessels in the skin and underneath and pulsation usually present. AVMs can invade the skin where ulcerations and bleeding are common. Most AVMs presenting before the age of 20 will have a history that includes the presence of a vascular blush in the overlying skin as a child that then began to expand and bleed. The history shows that the vascular lesion grew more rapidly as the patient entered puberty or had other hormonal changes. Patients over the age of 40 will often give a history of recent onset of the lesions not having been noticed previously. They may also give a history of trauma to the involved area prior to noticing it. Bleeding, pain, and tissue destruction are often subsequent signs in AVM growth, and patients suffer significantly when the malformation reaches this stage. (2) 


\section{International Journal of Science and Research (IJSR) \\ ISSN (Online): 2319-7064}

Index Copernicus Value (2015): 78.96 | Impact Factor (2015): 6.391

\section{Diagnosis}

AVMs can be diagnosed with Pulsed Doppler which documents the arterial output and can be used to follow the progression of an AVM. (4)

Magnetic resonance imaging (MRI) with T2-weighted processing will typically reveal a hyper intense, irregular lesion with numerous flow voids. (11)

Computed tomography arteriogram (CTA) can give excellent images of the AVM. CTA is preferred because it requires less time, is less expensive, and provides superior imaging capability for surrounding normal tissue and bone as compared with conventional MRA. In addition, digital processing of CTA can provide three-dimensional images of superficial AVM and demonstrate their primary arterial feeders. (2) (14)

\section{Management}

Many of the studies reported using arteriogram and embolization with varying substances, such as, glue, coils, and alcohol. (2) Surgical resection after embolization is another common treatment modality. This combination is indicated when the AVM is small and appears to be focal' and completely resectable. Surgery is also indicated in a very large AVM, which is life-threatening because of bleeding and invasion. (15) (16)(7)

Preoperative embolisation of the feeding arteries has been shown to reduce the hypervascularity and therefore, to aid surgical resection of these lesions. Recent developments in the design of micro catheters and distal navigation techniques have facilitated the catheterization of feeding arteries close to the nidus. (4) Longacre et al reported good results with intravascular embolisation of a facial haemangioma using silicone balls impregnated with barium or tantalum. (17) At present, the embolic materials generally employed are absorbable gelatin foam, polyvinyl alcohol (PVA), absolute alcohol, and NBCA. Gel foam is a temporary vessel occluder and will be resorbed in 1-2 weeks. (18) Polyvinyl alcohol is a permanent material and one of the most commonly used embolising agents. Direct puncture embolisation of the venous pouch of an AVM has the advantages of reducing the risk of ischemia (i.e., skin necrosis and compromise of the central retinal artery) and being technically simple when compared to transarterial embolisation. (4) (19)

Complications from embolisation are infrequently seen; however, necrosis of adjacent tissues may occur. Hence, patients must be adequately treated with broad-spectrum antibiotics. The most serious complication is the backflow of the embolus into the internal carotid or vertebral arteries as a result of circulatory sluggishness. A distal placement of the micro catheter close to the nidus will avoid this complication.

To conclude, super-selective embolisation followed by a complete surgical resection is the correct treatment for arteriovenous malformations on the facial region. Surgical resection of the vascular tumour should be performed with a skin-sparing incision to avoid disfigurement. Excision should be followed by primary closure whenever possible. Superficial tissue losses can be covered with a split thickness skin graft. Local tissue flaps (skin rotation flap for cheek) and Estlander's flap for the upper lip will give better cosmetic results. There may be a need for free tissue transfer in the reconstruction of more complex defects. After this combined modality of embolisation, followed by resection, the patient must be followed up for years by clinical examination, ultrasonography, and/or MRI. (4)

\section{References}

[1] http://en.wikipedia.org/wiki/Arteriovenous_malformatio

[2] LM Buckmiller, GT Richter, JY Suen Department of Otolaryngology, University of Arkansas for Medical Sciences, Little Rock, AR, USA

[3] Kohout MP, Hansen M, Prebaz JJ, Mulliken JB. Arteriovenous malformation of the head and neck: natural history and management. Plast Reconstr Surg. 1998;102:643-54.

[4] . P. S. Bhandari, L. P. Sadhotra, P. Bhargava, A. S. Bath, M. K. Mukherjee, and Sanjay Maurya Indian J Plast Surg. 2008 Jul-Dec; 41(2): 183-189.doi: 10.4103/0970-0358.44943

[5] Nekooie S, Hosseini M, Nazemi S, Talaei-khoei M, Embolisation of Arteriovenous malformations of maxilla. Dentomaxillofac Radiol 2006; 35:451-5

[6] Kohout MP, Hansen M et al (1998). Arteriovenous malformations of the head and neck: natural history and management. Plast Reconstr Surg 102: 643-654.

[7] Seccia A, Salgarello M et al (1999). Combined radiological and surgical treatment of arteriovenous malformations of the head and neck. Ann Plast Surg 43: 359-366.

[8] Neha Khambete, Mukund Risbud, Nikit Mehta Department of Oral Medicine, Diagnosis and Radiology, Vasantdada Patil Dental College and Hospital, Kavalapur, India S.D.M. College of Medical Sciences, Dharwad, India Imaging Science in Dentistry 2011; $41 \quad$ : $123-8$ http://dx.doi.org/10.5624/isd.2011.41.3.123

[9] Duyka LJ, Fan CY et al (2009). Progesterone receptors identified in vascular malformations of the head and neck. Otolaryngol Head Neck Surg 141: 491-495.

[10]Lee BB, Do YS et al (2004). Management of Arteriovenous malformations: a multidisciplinary approach. J Vasc Surg 39: 590-600.

[11] Wu JK, Bisdorff A et al (2005). Auricular Arteriovenous malformation: evaluation, management, and outcome. Plast Reconstr Surg 115: 985-995.

[12] Kim JY, Kim DI et al (2006). Surgical treatment for congenital arteriovenous malformation: 10 years' experience. Eur J Vasc Endovasc Surg 32: 101-106.

[13] Jeffree RL, Stoodley MA (2009). Postnatal development of Arteriovenous malformations. Pediatr Neurosurg 45: 296-304.

[14]Ziyeh S, Strecker R et al (2005). Dynamic 3D MR angiography of intra- and extracranial vascular malformations at 3T:a technical note. AJNR Am J Neuroradiol 26: 630-634.

\section{Volume 6 Issue 7, July 2017 www.ijsr.net}




\section{International Journal of Science and Research (IJSR) \\ ISSN (Online): 2319-7064}

Index Copernicus Value (2015): 78.96 | Impact Factor (2015): 6.391

[15] Bradley JP, Zide BM et al (1999). Large Arteriovenous malformations of the face: aesthetic results with recurrence control. Plast Reconstr Surg 103: 351-361

[16]Richter GT, Suen J et al (2007). Arteriovenous malformations of the tongue: a spectrum of disease. Laryngoscope 117: 328-335.

[17] Longacre JJ, Benton C, Unterthiner RA. Treatment of facial haemangioma by intravascular embolization with silicone spheres. Plast Reconstr Surg.1972;50:618-21

[18] Leikensohn JR, Epstein LI, Vasconez LO Plast Reconstr Surg. 1981 Aug; 68(2):143-52.

[19]Han MH, Seong SO, Kim HD, Chang KH, Yeon KM, Han MC Radiology. 1999 Jun; 211(3):661-6. 